\title{
Pontin/Tip49 acts as a novel regulator of JNK pathway
}

\author{
Xingjun Wang ${ }^{1,2}$, Xirui Huang ${ }^{1}$, Chenxi $\mathrm{Wu}^{3}$ and Lei Xue ${ }^{1}$
}

Pontin/Tip49, one of the superfamily members of the AAA + ATPases, is involved in many functions in cell contexts from invertebrates to mammals. Pontin is reported to play a role in cancer ${ }^{1,2}$ such as tumor inva$\operatorname{sion}^{3}$, regulation of growth and proliferation ${ }^{4}$, acts as a cofactor for Oct4-dependent lincRNA expression in stem cells ${ }^{5}$, yet its role in cell death remains poorly understood. In this Comment, we will discuss our recently published article about Pontin as a negative regulator of Egr-induced JNK-mediated cell death, which highlights a possible relationship between ATPase and $\mathrm{Egr} / \mathrm{JNK}^{6}$.

The c-jun N-terminal kinase (JNK) signaling pathway is highly conserved among species and governs diverse roles in animals, such as dorsal closure ${ }^{7-9}$, cell death ${ }^{10}$, tumor metastasis ${ }^{11-13}$, and progression of Alzheimer's Disease $^{14}$. To search additional regulators of the JNK pathway, we carried out a genetic screen in Drosophila for modulators of the tumor necrosis factor ortholog Eiger (Egr)-induced cell death ${ }^{10}$, and identified Pontin (Pont) as a negative regulator of the Egr-JNK pathway ${ }^{6}$. A mild expression of Egr in eye development induced weak cell death and produced a rough eye phenotype ${ }^{10}$, which could be enhanced to a small eye phenotype or suppressed to normal eye upon genetic modification, and thus, could serve as a powerful tool for genetic screen. We found that downregulation of pont by RNAi approach

\footnotetext{
Correspondence: Xingjun Wang (xwang@scripps.edu) or Lei Xue

(lei.xue@tongji.edu.cn)

${ }^{1}$ Institute of Intervention Vessel, Shanghai 10th People's Hospital, Shanghai Key Laboratory of Signaling and Diseases Research, School of Life Science and Technology, Tongji University, 1239 Siping Road, Shanghai 200092, China

${ }^{2}$ Department of Neuroscience, Scripps Research Institute, Florida 130 Scripps Way Jupiter, Florida 33458, USA
}

Full list of author information is available at the end of the article. dramatically enhanced GMR $>$ Egr-induced cell death and produced a small eye phenotype. This enhancement was confirmed in heterozygous pont mutants. Furthermore, depletion of pont induced JNK-dependent cell death and activated the expression of JNK target gene puc in wing development. As activation of JNK pathway in the developing thorax could induce cell death and generate a small notum phenotype, we wonder whether Pont also regulates JNK pathway in the thorax development. In line with this hypothesis, loss of pont in the developing thorax induced cell death and produced a small notum phenotype, which was suppressed in heterozygous mutants for bsk encoding the Drosophila JNK and fos encoding the AP-1 component, indicating that Pont is physiologically required to inhibit JNK-Fosmediated cell death in thorax development. To probe how Pont regulates the JNK pathway, we checked the activity of JNK by its phosphorylation, finding that depletion of pont in the wing disc resulted in elevated JNK phosphorylation, which was fully suppressed by the expression of Puc, a JNK phosphatase. Thus, endogenous Pont negatively regulates JNK-mediated cell death by inhibiting the phosphorylation of JNK.

Next, we examined if increaseed Pont is sufficient to suppress ectopic Egr-induced JNK-mediated cell death in development. We found expression of Pont suffice to block ectopic Egr-induced puc expression, cell death and morphological defects in the adult eye, wing and thorax, suggesting Pont inhibits Egr-triggered JNK activation and cell death in a non-tissue-specific manner. To characterize the epistasis of Pont in the Egr-JNK pathway, we checked the genetic interaction between Hep, a JNK kinase, and Pont. We found that gain of Pont compromised Hep-induced cell death phenotypes in the eye, thorax and wing, indicating Pont may act downstream of Hep. Collectively, this

(c) (i) Open Access This article is licensed under a Creative Commons Attribution 4.0 International License, which permits use, sharing, adaptation, distribution and reproduction in any medium or format, as long as you give appropriate credit to the original author(s) and the source, provide a link to the Creative Commons license, and indicate if changes were made. The images or other third party material in this article are included in the article's Creative Commons license, unless indicated otherwise in a credit line to the material. If material is not included in the article's Creative Commons license and your intended use is not permitted by statutory regulation or exceeds the permitted use, you will need to obtain permission directly from the copyright holder. To view a copy of this license, visit http://creativecommons.org/licenses/by/4.0/. 


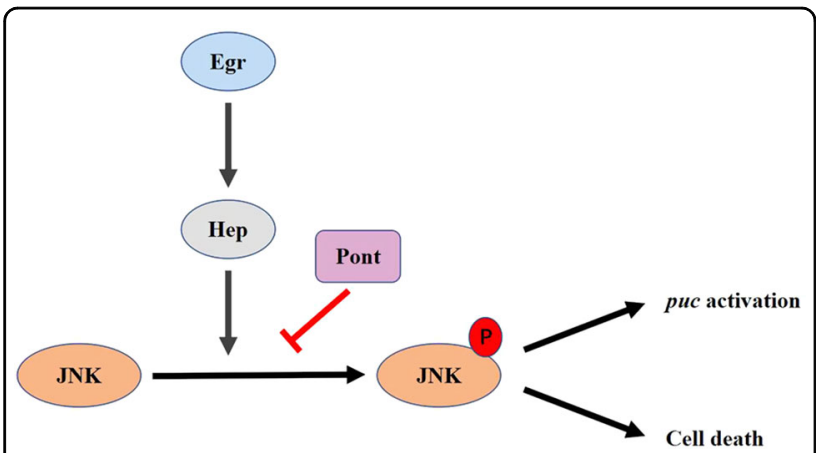

Fig. 1 The role of Pont in the Egr-JNK pathway. An illustration of Pont in the Egr-JNK pathway is shown. Pont inhibits Hep-triggered JNK phosphorylation, which leads to cell death and target gene puc expression

study highlights a novel role of Pont ATPase in the Egr-JNK pathway (Fig. 1).

\section{Acknowledgements}

We thank Dr. Peter Gallant, the NIG and the Bloomington Drosophila Stock Center for fly stocks. This research was supported by the National Natural Science Foundation of China (31571516, 31701244, 31771595), the Fundamental Research Funds for the Central Universities (2000219125), Shanghai Committee of Science and Technology (09DZ2260100, 18430711600), Natural Science Fund of Hebei Province of China (C2018209119), Scientific and Technological Research Project of Higher Education of Hebei Province (QN2017118) and Doctoral Scientific Research Foundation of North China University of Science and Technology (BS2017063).

\section{Author details}

'Institute of Intervention Vessel, Shanghai 10th People's Hospital, Shanghai Key Laboratory of Signaling and Diseases Research, School of Life Science and Technology, Tongji University, 1239 Siping Road, Shanghai 200092, China. ${ }^{2}$ Department of Neuroscience, Scripps Research Institute, Florida 130 Scripps Way Jupiter, Florida 33458, USA. ${ }^{3}$ College of Chinese Medicine, North China University of Science and Technology, 21 Bohai Road, Tangshan 063210, China

\section{Conflict of interest}

The authors declare that they have no conflict of interest.

\section{Publisher's note}

Springer Nature remains neutral with regard to jurisdictional claims in published maps and institutional affiliations.

Published online: 24 September 2018

\section{References}

1. Mikesch, J. H. et al. AAA+ ATPases Reptin and Pontin as potential diagnostic and prognostic biomarkers in salivary gland cancer-a short report. Cell Oncol. https://doi.org/10.1007/s13402-018-0382-8 (2018).

2. Mao, Y. Q. \& Houry, W. A. The role of Pontin and Reptin in cellular physiology and cancer etiology. Front. Mol. Biosci. 4, 58 (2017).

3. Sun, Q. et al. Pontin acts as a potential biomarker for poor clinical outcome and promotes tumor invasion in hilar cholangiocarcinoma. Biomed. Res. Int. 2018, 6135016 (2018).

4. Bellosta, P. et al. Myc interacts genetically with Tip48/Reptin and Tip49/Pontin to control growth and proliferation during Drosophila development. Proc. Natl Acad. Sci. USA 102, 11799-11804 (2005).

5. Boo, K. et al. Pontin functions as an essential coactivator for Oct4-dependent lincRNA expression in mouse embryonic stem cells. Nat. Commun. 6, 6810 (2015).

6. Wang, et al. Pontin/Tip49 negatively regulates JNK-mediated cell death in Drosophila. Cell Death Discover. 5, https://doi.org/10.1038/s41420-018-0074-1 (2019).

7. Kushnir, T. et al. Novel interplay between JNK and Egfr signaling in Drosophila dorsal closure. PLoS Genet. 13, e1006860 (2017).

8. Stronach, B. \& Perrimon, N. Activation of the JNK pathway during dorsal closure in Drosophila requires the mixed lineage kinase, slipper. Genes Dev. 16, 377-387 (2002).

9. Zeitlinger, J. \& Bohmann, D. Thorax closure in Drosophila: involvement of Fos and the JNK pathway. Development 126, 3947-3956 (1999).

10. Xue, L. et al. Tumor suppressor CYLD regulates JNK-induced cell death in Drosophila. Dev. Cell. 13, 446-454 (2007).

11. Wang, $X$. et al. Amyloid precursor like protein-1 promotes JNK-mediated cell migration in Drosophila. Oncotarget 8, 49725-49734 (2017).

12. Uhlirova, M. \& Bohmann, D. JNK- and Fos-regulated Mmp1 expression cooperates with Ras to induce invasive tumors in Drosophila. EMBO J. 25, 5294-5304 (2006).

13. Igaki, T., Pagliarini, R. A. \& Xu, T. Loss of cell polarity drives tumor growth and invasion through JNK activation in Drosophila. Curr. Biol. 16, 1139-1146 (2006).

14. Hong, Y. K. et al. Inhibition of JNK/dFOXO pathway and caspases rescues neurological impairments in Drosophila Alzheimer's disease model. Biochem. Biophys. Res. Commun. 419, 49-53 (2012). 